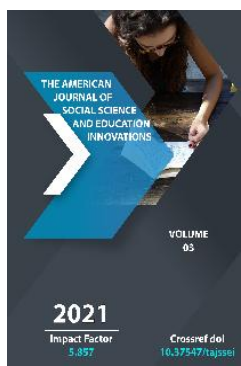

\title{
The Category Of Quantitativeness In Modern Linguistics
}

\author{
Karimova Shakhloza Boyquzi Qizi \\ Teacher Of The Department Of The English Language, Faculty Of Foreign Languages, Fergana \\ State University, Fergana, Republic Of Uzbekistan
}

\begin{abstract}
Journal Website:
http://theamericanjour

nals.com/index.php/taj

ssei

Copyright: Original content from this work may be used under the terms of the creative commons attributes 4.0 licence.
\end{abstract}

\section{ABSTRACT}

The article under discussion depicts the issues of the category of quantitativeness in modern linguistics. The author of the article examines separate parts of speech representing quantitative semantics and describes general categorical properties of quantification as a grouping of lexicogrammatical units of the natural language. Particular attention is paid to numerals and their pragmatic possibilities.

\section{KEYWORDS}

The category of quantitativeness, quantity, multitude, linguistics, parameters, a mental phenomenon, explore.

\section{INTRODUCTION}

The category of quantitativeness is one of the basic categories of human thinking, since all kinds and forms of matter are characterized by quantitative definiteness. The quantitative definition of a thing can refer both to its external attributes, i.e., magnitude, and characterize the internal nature of things (weight, heat capacity, etc.). The objects of reality themselves can be represented both in a single quantity and in a multitude.
The category of quantitativeness is one of the most important ontological categories permeating all human existence and is also a mental phenomenon, the result of human cognition of quantitative definiteness of the real world and active classification activity of human thinking, the result of reflection of objective quantity in consciousness, its conceptual analogue. 


\section{MAIN PART}

The study of the category of quantitativity goes back to ancient philosophy, and it was first presented in the works of Aristotle. Hegel developed the traditions of antiquity and defined the concepts of quantity, measure, and intensity, which are appropriate to the category of quantity and have been disseminated not only in philosophy, but also in linguistics. Linguists have continued to explore the category of quantity. In the classical works of linguistics, scholars deal with the problems of reflecting the category of quantitativeness in language, determining the linguistic means expressing quantitative meaning. The category of quantitativeness occupies all the layers of the linguistic structure - vocabulary, word formation, morphology and syntax.

The category of quantitativeness is a broader notion than that of quantity. Its ontological nature is conditioned by a variety of parameters of matter itself (sizes of objects, degree of manifestation of a sign and state, intensity of manifestation of action, measure as an initial stage of comparison of objects and concepts, etc.). As V. A. Maslova notes, "the picture of the world can be presented by means of spatial, temporal, quantitative, ethical and other parameters" [3, p. 49]. It is space, time and quantity that are the basis for the existence of the world and man. In the linguistic picture of the world quantitative and parametric properties of realities of the objective world are most vividly represented. This is an abstract quantity (people, speakers of languages, came to comprehend it not at once); and quantitative-parametric features of objects, expressed in the language in different ways: phonetic, word-formation, lexicosemantic, morphological and syntactic, and indefinitely large and indefinitely small quantities. Different languages have different ways of transmitting quantitative parameters $[1$, p. 526].

The choice of number forms is influenced by a whole complex of factors: cognitive (referential and non-referential use, type, gender, class values, use in generic utterances, etc.); denotative (correlation with the real number of discrete objects); systemic (formal syntactic subordination, etc.); pragmatic, connected with the speech sender's intentions (purposes of additional influence, form transposition - hyperbolic plural, etc.).

In natural language it is known that quantification is carried out differently in relation to discrete sets and non-discrete objects. In the first case the number of elements of a quantifiable set (two students, several houses, many books, many insects) is specified, and in the second case the object of quantification is the value of an object usually considered in terms of some measurement weight, volume, area (a kilogram of sugar, a liter of milk, thirty meters of living space).

In modern writings on grammar, one can find the claim that within collective names there is a neutralization between singularity and plurality, : "The concept of 'aggregate of persons' is not simple. Including the more elementary notions of 'person' and 'plurality', this notion is another case of the neutralization of the singularity/multiplicity opposition by collective nouns. First, it is not quite clear what kind of opposition we are talking about - the opposition of formal features (singularity-plurality inflexions) or semantic properties. The singular form (not only for collective names) is capable of conveying the idea of plurality (in standard language, in cases of the so-called generalized-collective singular or in cases of class meanings). These are, however, values 
that are not formed by an isolated form, but by many contextual conditions. Collective names, on the other hand, are capable of conveying the idea of multiplicity out of context, as dictionary units, so it is hardly legitimate to speak of "neutralization" in this case. Moreover, collective names in the singular are capable of transmitting superpowerful sets (at least, stronger than the corresponding plural form: man - people, but mankind; brother - brothers, but brotherhood).

The collective name is the intersection of all linguistic levels: lexical, as it carries certain knowledge about the object, and grammatical, as the implementation of certain rules of use in the discourse. Its irreducibility to the usual plural is associated with its inherent bright pragmatics - evaluative content and emotional coloring. Collective names belong to those units, the emotional significance of which is often created with the help of word-formation means. The evaluative and emotional are included in the pragmatics of a collective name as the opinions and feelings of those who interpret this linguistic sign.

The means of lexical plurality represent quantification in a highly detailed way: words like sea, river, ocean, heap, avalanche, stream, forest, bouquet and many others convey the subtlest semantic and pragmatic shades of quantification (an ocean of tears, forest of hands, sea of blood).

Through the forest of pointed black Hogwarts hats, Harry saw a long line of scared-looking first years filing into the Hall. (Rowling J.K. Harry Potter and the Chamber of Secrets).

In English, the smallest amount is often presented as a bit, "a little piece"; not a bit - "not a drop, not a crumb", have a wee bit of patience - "have a drop of patience".

The nouns used are those denoting objects of great volume, extent, or force: oceans, mountains, worlds, volumes, barrels, bucketfuls, hurricanes, etc., as well as nouns adjoining quantifiers: myriad - "unaccountable number, ten thousand", in droves - many people [2, p.125].

I feel a ton better since I landed here. The unemployed were coming to town in droves.

The category of intensification is a semantic category, which is based on the concept of gradation of quantity in the broad sense of the word.

The notion of intensification is related to the category of intensity, which has a subjective character. The reasons for choosing one or another intensifying means are also different individually. The degree of expressiveness of a statement can be graded by introducing intensifiers into its composition, which determine the measure of expressiveness of expressions: awfully, deplorably, desperately, dreadfully, helplessly, hopelessly, horribly, incredibly, miserably, pitiably, pitifully, remarkably, starkly, terribly, uncommonly, unusually, wretchedly poor [4, p. 15].

The choice of the intensifier, which is not so much a dictum as a modus, is determined by the addressee's attitude to the subject of speech, as well as by individual (or group, style) preferences. The general or selective compatibility of lexical intensifiers with the word being defined also plays a role.

Normative intensifiers usually have no special means of manifestation, whereas there are many specialized means for expressing the intensity of a sign. Similar intensifiers may be 
characteristic of a number of languages (in Uzbek qo'rqinchli, dahshatli, in Russian страшный, ужасный, in English, awful, fierce, terrible). Similar intensifiers are often used in translation:

"Poor little thing!" said Alice, in a coaxing tone, and tried hard to whistle to it; but she was terribly frightened all the time at the thought that it might be hungry, in which case it would be very likely to eat her up in spite of all her coaxing. (L. Carroll. Alice in Wonderland).

However, most means of intensification are nationally specific; in Uzbek kuchli/qattiq (sovuq, tuman, shovqin, hayajon, taassurot, og'riq), in Russian сильный (мороз, туман, шум, волнение, впечатление, боль) and in English heavy (rain, smog, sound, crop, traffic, foliage).

The category of intensity is associated with all levels of language - from phonetic to syntactic. The high degree of the feature is interpreted as distance from the referential (neutral) point and is marked by lengthening:

For example: How beautiful is she! or "Idiotic!" said George, banging the end of his walking-stick on the ground; "ab-so-lute-ly idiotic!.." (Aldington) [4, p. 21].

In this emotional retort, the emphase falls on the lexical intensificator, the adverb ab-solute-ly, which adds little to the emotional evaluation expressed by the adjective idiotic.

The ability of particles to create additional pragmatic meanings that accompany quantitative evaluation is well known. It is interesting that in translated texts intensifying particles often appear to intensify the utterance.
For example: "I was only Crown Prince then. I was young. I am but thirty now." (A. Conan Doyle. A Scandal in Bohemia) [4,5].

The quantificative semantics of the particle creates an antithetical construction: Their brain is seething with ideas, and they can on-ly tell you that the umbrella of the gardener's aunt is in the house. (W.S. Maugham. The Moon and Sixpence) [4, p. 20].

Thus, functional parts of speech, the semantic content of which includes the senses "much" and "little," take part in the expression of quantificative meanings.

\section{CONCLUSION}

Quantification is a quantitative characteristic of reality fixing separability, singularity and multiplicity of quantifiable objects and gradation of fragmented qualities and processes by correlation of part and whole, size, duration, intensity; it is based on dialectical antinomy of continuity and discreteness and logical comparison operation and is conceptualized as a universal cognitive category of quantity getting variant expression in the content of language units.

\section{REFERENCES}

1. Khairullina R. Kh., Rakhimova E. F., Sagitova A. F. (2018). Mir nauki, kul'tury, obrazovaniya. №. 3(70). p.p. 525-528.

2. Gailomazova E.S. (2010). Pragmatic Content of Numerals. Humanities and socio-economic sciences. № 6. p.p. 125-132.

3. Maslova V. A. (1997). Vvedenie v lingvokul'turologiyu [Introduction to linguoculturology]. Moscow: Nasledie. P.78. (in Russian). 
4. Sapir E. (1981). Language, an introduction to the study of speech. New York. pp.6-13.

5. Wierzbicka A. (1988). The semantics of grammar. Amsterdam; Philadelphia: John Benjamins B.V. p.p. 4-25.

6. Amos, H. W., \& Soukup, B. (2020). Quantitative 2.0: Towards Variationist Linguistic Landscape Study (VaLLS) and a standard canon of LL variables. InD. Malinowski \& S. Tufi Eds. Reterritorializing Linguistic Landscapes: Questioning boundaries and opening spaces, 56-66. 